\title{
Factors stimulating open innovation
}

\author{
Tayfun Arar ${ }^{a^{*}}$ and Melahat Öneren
}

${ }^{a}$ Research Assistant, Kirlkkale University, Turkey ${ }^{b}$ Assistant Professor, Kirlkkale University, Turkey

CHRON I CLE ABSTRACT

Article history:

Received October 28, 2015

Received in revised format

November 28, 2015

Accepted January 2, 2015

Available online

January 3, 2016

Keywords:

Open innovation

ELECTRE III

Inbound innovation

Outbound innovation

\begin{abstract}
The term innovation which is about the novelty on products, processes, services, technologies, on strategies or organizational structures is important for companies to stay in the competition and run their businesses well to gain both financial and organizational achievements. By the changing and globalizing world, innovation may require some interaction and cooperation which is called open innovation. In this research, five factors including brainstorming, feedback, benchmarking, open-minded mentality and relationship with supply chain elements triggering open innovation are investigated and ranked by one of the multi-criteria decision making models called ELECTRE III according to two criteria of inbound and outbound innovations.
\end{abstract}

C 2016 Growing Science Ltd. All rights reserved.

\section{Introduction}

Day by day, new products are made or the present ones are modified to a better position. Not only in products, but also for other companies such as service firms are finding new ideas and applying those to their customers to create values and to step up to their competitors. Both manufacturing and service companies are also developing novelties either on their processes, technologies they use, strategies or on the entirely of their organizational structures. All of these innovative operations are made to stay in the competition. But these innovative processes should not be limited within the organization boundaries in this fast varying and uncertain environment (Kaynak \& Maden, 2012). This situation has caused the carrying up the term innovation to the term open innovation which requires the efforts accomplished for the sake of innovation should be shared with other corporations and companies as both communication and information sharing (Kaynak \& Maden, 2012). According to Chesbrough (2006) open innovation is; while providing the inbounding and out bounding the valuable information to expediting the internal innovation, making the markets as places where the innovation is used as external.

* Corresponding author. Tel: +90 5383647911 
Though the topic innovation has been studied through many years both empirically and theoretically; open innovation can be assumed as a new topic and that is why there are still researches made on this issue. Also in this study, while making the literature review, it can be obviously seen that all of the studies investigated were made after 2006 and mostly after 2013. When the topic is about innovating, the first thing comes to minds is technology. Although there are researches about open innovation on technological - scientific products or sectors. Paik and Chang's (2014) examined how the open innovation approaches and strategic fit by means of innovation effects of the external resources and network situations of smartphone manufacturers' functions in delivering innovation outcomes and business performance. Michelino et al.'s (2015) made an investigation on the openness of biopharmaceutical sector firms. Hu et al.'s (2014) investigated the outbound open innovation of firms engaged in technological venturing. Nevertheless, it does not mean that this topic is only associated with technological products and it is related to any company in any sector such as Pellegrini et al.'s (2014) research who investigated open innovation in food and drink industry by developing a regression model on innovation performance. They reported that this sector could be indicated as a sector under increasing pressure to open up.

Some studies have been made to help strategists benefit from the open innovation while not experiencing any drawbacks of it. Coras and Tantau's study (2014) aimed to contribute to the scarce literature on open innovation risks and to shed light on the factors that a firm needs to approach in order to foster a culture for open innovation and, in the same time, to reduce the drawbacks of open innovation. In that research also the motives to open innovation were investigated. Pauolose and Nair study (2015) conceptualized a framework that would help strategists position their firm in the market by carefully analyzing its interactions with other business and social entities in the concept of open innovation in the business eco-system. In Salter's (2014) study; four specific challenges and coping strategies of individuals engaged in open innovation are identified and the sudy proposes an arrangement of open innovation practices that organizations can implement to better equip their staff to undertake effective external engagement. According to Colin et al. (2014), having a more explicit strategic orientation enhances the effectiveness of open innovation; when comparing the three strategic orientations, entrepreneurial orientation strengthens the positive performance effects of open innovation significantly more than market orientation and resource orientation do. Huang et al. (2015) studied external factors affecting the open innovation and found out that external heterogeneity has a bad effect on open innovation.

There are also many studies about open innovation to show its importance. Kaynak and Maden's (2012) research which aims to describe the open innovation concept through innovation concept and then, embrace different approaches about open innovation and innovation process and reasons of necessity of innovation. Kondev et al.'s (2014) investigated the competitiveness by making and using open innovation model. Chesbrough et al.'s (2014) case study allows students to learn how a small firm thrived and became a business success based on building a successful business ecosystem that shares knowledge, encourages individuals' growth, and embeds trust among participants; Gianiodis et al.'s (2014) findings that the two banks' deployment of open innovation processes produced strong results including greater top-line growth and bottom-line efficiency gains; Martinez's (2013) focus on open innovation's importance by pointing out that it creates value for each firms considered in this cooperation under the name of competitive advantage. On the other hand there are also some researches about the disadvantages of open innovation such as Whelan et al.'s (2014) focuses on the dark side of the open innovation systems just like information overload, knowledge leakage and intellectual property issues.

The term "open innovation" was first used in 2003 by Chesbrough who defined the traditional innovation as a close innovation (Kaynak \& Maden, 2012). Today the key of the success is provided, when applied properly, by sharing. This sharing could be about information, raw material, ideas, people, power, labor, money, etc. Even when thinking individually, a person cannot have idea about everything and when $\mathrm{s} /$ he gets stucked $\mathrm{s} /$ he asks for help. Like people in present time, businesses may 
also ask for help such as they prefer outsourcing instead of acquiring the raw material or the supplements to produce their main products. They also ask for counseling from the companies which exist for this, and make important decisions according to these suggestions. The world is changing so fast ever, that is why products we use, services we expect to have or when considering the business life professionally, to stay in the competition, to be proactive instead of being reactive, businesses try to innovate things such as strategies, structures, products and services they present to their customers. As mentioned before, because the key of success is coming through of sharing, the term innovation is transforming to a new term that is open innovation. Though for some researches this term is still new and may have some bad effects like information overload, knowledge leakage and intellectual property issues (Whelan et al., 2014); according to Wallin and Krogh (2010), with open innovation; businesses decrease the cost of product development and process improvement, gains time in new products when launching them to the market, improve the quality of product and heal up the relationships with the customers and suppliers. Firms which use open innovation also can complement their research and development (R\&D) efforts with those of outside partners and can intermediate innovations through licensing (Colin et al., 2014). Open innovation can also reduce risks by sharing them with the partners and exploit diversity of products and services (Coras \& Tantau, 2014). While it lets organization gain needed skills, technologies, assets, and other resources from partners' side; with the sharing of resources, firm's capability and flexibility of conducting its innovative projects enhances (Coras \& Tantau, 2014). Open innovation also means the novelty; and one of the reasons which require businesses to pass through is the products and services those are getting more complex and this situation makes the innovators come together (Battisti et al., 2014).

Of course, applying open innovation may lead to more success in some firms or in some sectors and the degree of openness may vary (Michelino et al., 2015). In sectors where the information is so important and should not be shared because of some unethical forge ahead in the competition-issues; open innovation is not suggested. Moreover in those sectors, businesses close their information-doors to the out-world. At all, because with open innovation, businesses gain competitive advantage to their rivals, a business firm which has decided to open up its innovation process needs to know which factors trigger it; and how much importance it has in which conditions. In the light of this purpose, in this research, the factors driving firms to open innovation are found and ranked and chosen the most powerful factor on each criterion with the ELECTRE III method.

\subsection{Factors Playing Roles on Open Innovation}

In this research, five main factors those triggering open innovation are defined. These are brainstorming, feedback, benchmarking, open minded mentality and good relationships with supply chain elements.

\subsubsection{Brainstorming}

Brainstorming means an overcoming of pressures for conformity in an interacting group that delay the development of creative alternatives; by utilizing an idea generation process; it encourages the ideas that the majority accepts (Robbins \& Judge, 2009). An example of this situation has happened for Vienna's touristic strategy in 2020 which is about the travelers from all over the world, tourism experts and the Viennese having been invited to take part in an open innovation project called as "now or never: your idea \#Vienna2020 for an ideas competition for new, unconventional and provocative proposals for the destination Vienna; according to the director of tourism, Norbert Kettner the objective of their open innovation approach is to set new standards in destination development, and go new ways in marketing (Vienna Tourist Board, 2014).

\subsubsection{Feedback}

Open innovation research area does not only consider the innovation collaboration among the business firms; it also includes all possible collaboration ways among organizational ecosystems which are 
ranging from suppliers of raw materials, equipment, and research institutes to consumers and customers (Martinez, 2014). The flow of the relationship between the customers and the business firms do not always happen in a direction which is from the firm to the customer. To understand in which situation the firm is among the target people who are constituted by the customers and to be seen whether what the firm does catch the achievement or not objectively; and if there is something wrong, to make it right, business firms need some criticism and some turns about what they offer to their customers either in positive or negative way which is called the feedback. High-quality interactions that enable consumers to co-create unique experiences with companies which the companies themselves may not think are the key to unlocking new sources of competitive advantage (Martinez, 2014). At all, a business firm which considers the feedback from its customers will benefit from this when deciding the "open innovation".

\subsubsection{Benchmarking}

Benchmarking is the search for the best practices among the environmental neighbors who are either the competitors or non-competitors which does something that leads them to their superior performance (Robbins \& DeCenzo, 2008). The basic idea underlying of this concept is that management can improve quality by making analysis and then copying the methods of the leaders in various fields and finally applying the ones which fit themselves. That is why it can be called as a scanning of the environment (Robbins \& DeCenzo, 2008). Open innovation requires the exchange of knowledge across social and individual networks, both inside and outside the organization. By benchmarking, a business firm may embrace the solutions of how to overcome the deficiencies of it from another firm. The overcoming of this deficiency may accelerate the open innovation process if it somehow hinders that process. The another way the benchmarking is useful in this open innovation area is, when the firm compares it's and its competitors' situations and compare what each of the successful ones does, it can apply those in innovating the product, process, technology, service and so on.

\subsubsection{Open Minded Mentality}

This is about the range of the firm' or the top managers' of this firm interests and fascination with novelty (Robbins \& Judge, 2009) and ability to apply what the outsiders suggest for their wellness. Because if the business firm or the ones who manage it are conservative and closed to the ideas coming from the outside or if they believe that they know the best of everything and do not need anyone, then it will be hard to talk about open innovation. A business firm who decided to apply open innovation with a collaboration of its network, should be open to a new ideas, opinions, suggestions; consider them carefully and with an analysis such as Strength-Weakness-Opportunity-Threats Analysis (SWOT) properly prepared by the experts, by examining the opportunities that it could not realize by itself and strengths; the innovation process not only from internal but also from the external dynamics will accelerate.

\subsubsection{Relationship with Stakeholders-Ability of Collaboration \& Cooperation}

According to Coras and Tantau (2014); one of the main triggers of open innovation is the good communication among the stakeholders. The improvement which facilitates this is the increasing usage level of technological communication tools such as Web conferencing, instant messaging, Internet and social networking (Coras \& Tantau, 2014). For Collins (2006); the key to successful innovation lies as much in the ability to collaborate as it does the ability to perform applied science and engineering. When the relationship among the stakeholders or the elements in whole supply chain which is constituted by the suppliers, distributors, customers and even competitors is good, it means there is a respect and trust between the stakeholders and there is an effective collaboration and cooperation among them. That is so; trust plays an important role for assisting the process of smooth flow of information between different parties; moreover, beyond trust within organizations, the increasingly frequent cooperation and collaboration among organizations requires high degrees of trust among 
different parties (Shamah \& Elsawaby, 2014). Therefore, investigating the role of trust in supply chains and its impact on collaboration provides a better insight into supply chain management (Shamah \& Elsawaby, 2014) and this leads to a more effective open innovation.

\subsection{Criteria Considered in Open Innovation Issues}

In the light of the alternatives mentioned above, they will be examined under two criteria which are two possible types of open innovation inbound open innovation and outbound open innovation.

\subsubsection{Inbound Open Innovation}

Inbound open innovation or which may be called as outside-in activities refer to the ability to gain and explore knowledge from external partners. These partners may include suppliers, customers, competitors, consultants, research institutes, universities, or governments (Colin et al., 2014). Also for Granstrand and Holgersson (2014); inbound open innovation is to acquire the information and opinions from external sources. According to a research made in Europe (Battisti et al., 2014); innovation followers rely more extensively on external sourcing of knowledge and new ideas (with decreasing returns to innovation performance), and tend not to export and this shows those firms which are concerned in the search prefers this type of innovation.

\subsubsection{Outbound Open Innovation}

Inside-out activities encompass activities involved in external exploitation of internal ideas, for example by licensing out, selling of knowledge, and divestment of parts of the firm, such as spinning off innovation projects into new create innovative firms (Colin et al., 2014). According to Granstrand and Holgersson (2014); outbound innovation is relying on external roads to markets for misuse.

\section{Method}

In this research, to rank the factors in a hierarchical order triggering the open innovation ELECTRE III method is used and scoring is made according to a manager of a tractor manufacturer company's export \& import manager who is in charge of innovation of the company. The technique is a multicriteria decision making approach based on priority relationship and including imprecise, indeterminate and uncertain criteria and modeling complex decision processes by using pseudocriteria. In this technique there are alternatives and criteria. Each alternative gains some score for each criteria (Pena \& Oliveras 2007). Each criterion has a weight for itself. Weights should be equal to 1 at the total. There are also preference threshold ( $p$ value), indifference threshold ( $q$ value) and veto threshold ( $v$ value) for each criterion. After calculating the matrixes, a distillation method is used then the results where we can see the factors of resisting to the change in a hierarchical order. In this research scoring are made between the numbers 1-10. Here are the main relationship rules (Pena \& Oliveras, 2007):

If the performance scores' difference of two alternatives is less than the indifference threshold, a and $\mathrm{b}$ is indifferent $(a \operatorname{Ib}$ if $g(a)-g(b) \leq q)$

If the performance scores' difference is between the indifference and preference threshold, a is weakly preferred to $\mathrm{b}(a Q b$ if $q<g(a)-g(b)<p)$

If the performance scores' difference of two alternatives is more than the preference threshold, a is preferred to $\mathrm{b}(a \mathrm{~Pb}$ if $g(a)-g(b) \geq p)$

With ELECTRE III method, ordering of the alternatives based on priority is done by three steps. These are: 
- Preparation Process

In this process, each alternative is scored for each criterion. $a$ is used to identify the alternatives and $g$ is used to identify the criterion. $A=(a, b, c, \ldots, n)$ and $G=\left(g_{1}, g_{2}, \ldots, g_{n}\right) . a \in A$ alternative's performance according to $\mathrm{g}_{\mathrm{j}}$ criterion is showed by $g_{j}\left(a_{j}\right)$. Also, $w_{j}$ which is the weight of each criterion is identified. Finally, for each criterion; preference $(p)$, indifference $(q)$ and veto $(v)$ threshold values are identified.

\section{- Identification of the Priority Process}

In ELECTRE III method, by using threshold values, S priority relationship is developed. ASB means $a$ is, at least, as good as $b$. To accept this ASB, two standards are taken as -important.

Concordance Standard: Big part of the criteria is consistent with ASB phrase.

Discordance Standard: None of the inconsistent criteria rejects the ASB phrase strongly.

1) Concordance indexes of each pair of alternative $(a, b)$ for each criterion is procured by:

$c_{j}(\mathrm{a}, \mathrm{b})=1 \quad$ if $\quad g_{j}(\mathrm{a}) \geq g_{j}(\mathrm{~b})-q_{j}$

$c_{j}(\mathrm{a}, \mathrm{b})=0 \quad$ if $\quad g_{j}(\mathrm{a}) \leq g_{j}(\mathrm{~b})-p_{j}$

or else $\quad\left[g_{j}(\mathrm{a})-g_{j}(\mathrm{~b})+p_{j}\right] /\left(p_{j}-q_{j}\right)$

2) Cumulative concordance index $\mathrm{C}(\mathrm{a}, \mathrm{b})$ give information about the claim that a is prior to $\mathrm{b}$. When this claim is equal to 1 , it means it is true; if it is equal to 0 , then it means it is wrong.

$\mathrm{C}(\mathrm{a}, \mathrm{b})=\frac{\sum_{1}^{n} w_{j} c_{j}(\mathrm{a}, \mathrm{b})}{\sum w_{j}}$

3) Discordance indexes of each pair of alternative $(a, b)$ for each criterion is procured by:

$d_{j}(\mathrm{a}, \mathrm{b})=0 \quad$ if $g_{j}(\mathrm{a}) \geq g_{j}(\mathrm{~b})-p_{j}$

$d_{j}(\mathrm{a}, \mathrm{b})=1 \quad$ if $g_{j}(\mathrm{a}) \leq g_{j}(\mathrm{~b})-v_{j}$

or else $\quad \frac{\left[g_{j}(\mathrm{~b})-g_{j}(\mathrm{a})-p_{j}\right]}{\left(v_{j}-p_{j}\right)}$

4) With credibility matrix, final priority relationship is set:

$\mathrm{S}(\mathrm{a}, \mathrm{b})=\mathrm{C}(\mathrm{a}, \mathrm{b}) \quad$ if $\quad d_{j}(\mathrm{a}, \mathrm{b})<\mathrm{C}(\mathrm{a}, \mathrm{b}), \quad \mathrm{j}$

Or else $\mathrm{S}(\mathrm{a}, \mathrm{b})=\mathrm{C}(\mathrm{a}, \mathrm{b}) \Pi \frac{\left(1-d_{j}(\mathrm{a}, \mathrm{b})\right.}{1-\mathrm{C}(\mathrm{a}, \mathrm{b})}$

\section{- Ordering Process}

Credibility scores which are procured for each pair of the alternative constitute an input for distillation process to use for ordering the alternatives. This process is the combination of two preorder processes. First pre-order is the decreasing distillation which is built to show the alternatives from the best to the worst; second pre-order is the increasing distillation which is built to show the alternatives from the worst to the best. By combining these two, a final order is built. Distillation process steps are: 
1) The biggest value of the credibility matrix is identified as $\lambda 0 . \lambda 0=\max S(a, b)$

2) $s(\lambda 0$.$) -sortation threshold is calculated by the formula: s(\lambda 0)=.\alpha+\beta .0,3$ is used for $\alpha ;-0,15$ is used for $\beta$.

3) The upper bound of the sortation level is calculated by the formula: $\lambda 0-s(\lambda 0$.

4) $\lambda 1$ is identified as the maximum credibility matrix value less than the sortation level upper bound. $\lambda 1 .=\max S(a, b)$

5) After calculating the $\lambda 1$, values of the alternatives in the credibility matrix are compared with this value,

T-distillation matrix is procured:

$\mathrm{T}(\mathrm{a}, \mathrm{b})=1$ if $\mathrm{S}(\mathrm{a}, \mathrm{b})>\lambda 1$ and $\mathrm{S}(\mathrm{a}, \mathrm{b})-\mathrm{S}(\mathrm{b}, \mathrm{a})>\mathrm{s}(\lambda 0.) \mathrm{T}(\mathrm{a}, \mathrm{b})=0$ or else.

6)In distillation matrix, $T(\mathrm{a}, \mathrm{j})$ values are summed up in the row where each alternative belongs to (shows the strength of the alternative a) and also $T(\mathrm{j}, \mathrm{a})$ values are summed up in the column where each alternative belongs to (shows the weakness of the alternative $a$ ). Difference of the strength and weakness scores gives the net score of the alternative a.

7) In the decreasing distillation process, the alternatives whose net score is the highest constitute the distillation subsets. (In the increasing distillation process, these alternatives are the lowest scored ones.)

a) If there is only one alternative in the subset, this alternative is ordered as the best and the values of the row and the column of this alternative in the credibility matrix are made " 0 " and extracted from the analysis. For the remaining alternatives, it is required to return back to the beginning of this step.

b) If there are more than an alternative in the subset, only for this subset, it is required to return back to the beginning of this step, and needed to lower the sortation level, $\lambda 0$ is procured by using. $\lambda 1$ which is procured in the previous section. Then only for this subset, the process above is repeated from the second step till the $\lambda 1$ is equal to 0 .

I) If there is only one alternative remaining, this alternative is ordered as $7 \mathrm{a}$ and the values of this alternative in the credibility matrix is made 0 and continue the process

II) If there are more than one alternative in the subset and if the $\lambda 1$ is equal to 0 , it is understood that, an order cannot be made among the alternatives and can be said that these alternatives have the same hierarchy.

8) By both increasing and decreasing distillation processes results are combining a final order is procured. If $a$ gets a better score than $b$ in both distillation than we can say $a$ is preferred to $b(\mathrm{aPb})$; if $b$ gets a better score than the $a$ in both distillation than we can say $a$ cannot be preferred to $b$. If in one distillation $a$ gets a higher score, and in the other gets a lower score than we can say $a$ cannot be compared to $b(\mathrm{aRb})$. If $\mathrm{a}$ and $\mathrm{b}$ is at the same position in both distillation than $a$ and $b$ are indifferent (alb). In this research there are 5 factors those triggering the open innovation which are brainstorming, feedback, open minded mentality, relationship with supply chain elements and benchmarking. Criteria are inbound innovation and outbound innovation. Thus the model would seem alike: 


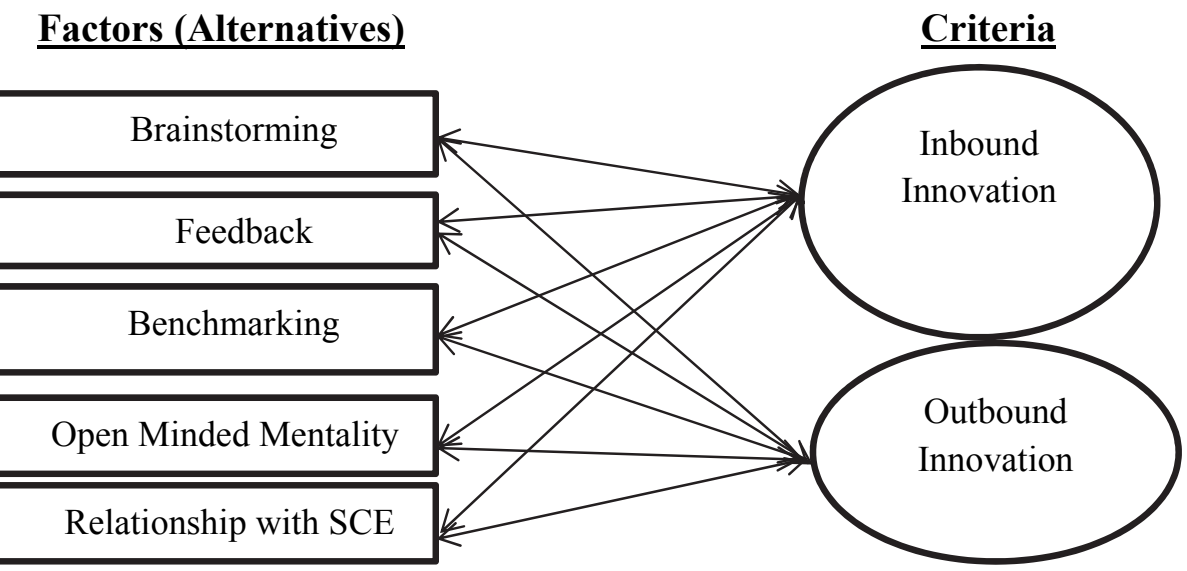

Fig. 1. Factors and Criteria of the Model

\section{Results}

First step is the scoring process of each alternative under each criterion as in Table 1.

Table 1

Raw scores of each alternative for each criterion

\begin{tabular}{ccc}
\hline Alternatives(Factors)/Criteria & Inbound Innovation & Outbound Innovation \\
\hline Brainstorming & 9 & 7 \\
Feedback & 10 & 10 \\
Benchmarking & 10 & 7 \\
Open Minded Mentality & 7 & 5 \\
Relationship with SCE & 10 & 10 \\
Weights & 0,6 & 0,4 \\
Q Value & 1 & 2 \\
P Value & 2 & 3 \\
V Value & 3 & 4 \\
\hline
\end{tabular}

As seen from Table 1 the weight of inbound innovation is higher than the outbound innovation. The reason of this is both by the preference of manager of the company and the general preference of the organizations in means of getting information from outside rather than sharing it. Indifference (Q), Preference $(\mathrm{P})$ and Veto $(\mathrm{V})$ values have been determined by the authors based on the scores decisions made by the manager of the company. Next step is building up the concordance matrices for each criterion as seen in Table 2 and Table 3.

\section{Table 2}

Concordance matrix for the criterion inbound innovation

\begin{tabular}{lccccc}
\hline Inbound Innovation & Brainstorming & Feedback & Benchmarking & Open Minded Mentality & Relationship with SCE \\
\hline Brainstorming & - & 1 & 1 & 1 & 1 \\
Feedback & 1 & - & 1 & 1 & 1 \\
Benchmarking & 1 & 1 & - & 1 & 1 \\
Open Minded Mentality & 0 & 0 & 1 & - & - \\
Relationship with SCE & 1 & 1 & 1 & - \\
\hline
\end{tabular}

\section{Table 3}

Concordance matrix for the criterion outbound innovation

\begin{tabular}{lccccc}
\hline Outbound Innovation & Brainstorming & Feedback & Benchmarking & Open Minded Mentality & Relationship with SCE \\
\hline Brainstorming & - & 0 & 1 & 1 & 1 \\
Feedback & 1 & - & - & 1 & 1 \\
Benchmarking & 1 & 0 & 1 & - & 0 \\
Open Minded Mentality & 1 & 0 & 1 & 1 & 0 \\
Relationship with SCE & 1 & 1 & - & 1 \\
\hline
\end{tabular}


According to concordance matrices, cumulative concordance matrix has been built up in Table 4 .

Table 4

Cumulative concordance matrix

\begin{tabular}{cccccc}
\hline & Brainstorming & Feedback & Benchmarking & Open Minded Mentality & Relationship with SCE \\
\hline Brainstorming & - & 0,6 & 1 & 1 & 1 \\
Feedback & 1 & - & 1 & - & 1 \\
Benchmarking & 1 & 0,6 & 0 & 1 & - \\
Open Minded Mentality & 0,4 & 0 & 1 & 1 & 0,6 \\
Relationship with SCE & 1 & 1 & - & 0 \\
\hline
\end{tabular}

The next step is building up the discordance matrices for each criterion in Table 5 and Table 6 .

Table 5

Discordance matrix for the criterion inbound innovation

\begin{tabular}{lccccc}
\hline Inbound Innovation & Brainstorming & Feedback & Benchmarking & Open Minded Mentality & Relationship with SCE \\
\hline Brainstorming & - & 0 & 0 & 0 & 0 \\
Feedback & 0 & - & 0 & 0 & 0 \\
Benchmarking & 0 & 0 & - & 0 & 0 \\
Open Minded Mentality & 0 & 1 & 1 & - & 1 \\
Relationship with SCE & 0 & 0 & 0 & 0 & - \\
\hline
\end{tabular}

\section{Table 6}

Discordance matrix for the criterion outbound innovation

\begin{tabular}{lccccc}
\hline Outbound Innovation & Brainstorming & Feedback & Benchmarking & Open Minded Mentality & Relationship with SCE \\
\hline Brainstorming & - & 0 & 0 & 0 & 0 \\
Feedback & 0 & - & 0 & 0 & 0 \\
Benchmarking & 0 & 0 & - & 0 & 0 \\
Open Minded Mentality & 0 & 1 & 0 & - & 1 \\
Relationship with SCE & 0 & 0 & 0 & 0 & -
\end{tabular}

Then credibility matrix is built up as seen in Table 7 .

\section{Table 7}

Credibility matrix

\begin{tabular}{lccccc}
\hline & Brainstorming & Feedback & Benchmarking & Open Minded Mentality & Relationship with SCE \\
\hline Brainstorming & - & 0,6 & 1 & 1 & 0,6 \\
Feedback & 1 & - & 1 & 1 & 1 \\
Benchmarking & 1 & 0,6 & - & 1 & 0,6 \\
Open Minded Mentality & 0,4 & 0 & 0 & - & 0 \\
Relationship with SCE & 1 & 1 & 1 & 1 & - \\
\hline
\end{tabular}

According to credibility matrix some $\lambda$ values are calculated in Table 8 .

Table 8

$\lambda$ Values

\begin{tabular}{cc}
\hline$\lambda \mathrm{o}$ & 1 \\
$\mathrm{~s}(\lambda 0)$ & 0,15 \\
$\lambda 0-\mathrm{s}(\lambda 0)$ & 0,85 \\
$\lambda 1$ & 0,6 \\
\hline
\end{tabular}

And the last steps are descending (Table 9 and Table 10) and ascend (Table 11 and Table 12) distillation matrices building, making comparison and deciding the final order.

Table 9

Descend distillation matrix

\begin{tabular}{ccccccccc}
\hline & $\mathrm{Br}$ & $\mathrm{F}$ & $\mathrm{Be}$ & OMM & RwSCE & Sum of Row & Sum of Col & $\mathrm{N}$ \\
\hline Brainstorming & - & 0 & 0 & 1 & 0 & 1 & 2 & -1 \\
Feedback & 1 & - & 1 & 1 & 0 & 3 & 0 & $3^{*}$ \\
Benchmarking & 0 & 0 & - & 1 & 0 & 1 & -1 & 2 \\
Open Minded Mentality & 0 & 0 & 0 & - & 0 & 0 & 4 & -4 \\
Relationship with SCE & 1 & 0 & 1 & 1 & - & 3 & 0 & $3^{*}$ \\
\hline
\end{tabular}


According to Table 9, maximum values of $N$ are chosen and left from the descend distillation process and as being a sub-matrix they are solved. After that process it is seen that those two alternatives have same importance of fostering open innovation and are positioned at first place. Then the same processes are done for the rest of the alternatives and the same situation mentioned above has been met for the other two alternatives those are brainstorming and benchmarking. They are also positioned at the second place. The last alternative takes the third place. According to descend distillation matrix, final situation is seen in Table 10.

Table 10

Descend distillation matrix (Final Situation)

\begin{tabular}{cc}
\hline Place & Alternative \\
\hline 1 & Feedback \\
1 & Relationship with SCE \\
2 & Brainstorming \\
2 & Benchmarking \\
3 & Open Minded Mentality \\
\hline
\end{tabular}

To check whether the process of descend distillation matrices are correct, ascend distillation matrices' processes are done.

Table 11

Ascend distillation matrix

\begin{tabular}{|c|c|c|c|c|c|c|c|c|}
\hline & $\mathrm{Br}$ & $\mathrm{F}$ & $\mathrm{Be}$ & OMM & RwSCE & Sum of Row & Sum of Col & $\mathrm{N}$ \\
\hline Brainstorming & - & 0 & 0 & 1 & 0 & 1 & 2 & -1 \\
\hline Feedback & 1 & - & 1 & 1 & 0 & 3 & 0 & 3 \\
\hline Benchmarking & 0 & 0 & - & 1 & 0 & 1 & 2 & -1 \\
\hline Open Minded Mentality & 0 & 0 & 0 & - & 0 & 0 & 4 & $-4 *$ \\
\hline Relationship with SCE & 1 & 0 & 1 & 1 & - & 3 & 0 & 3 \\
\hline
\end{tabular}

According to Table 11, minimum value of $N$ is chosen and left from the ascend distillation process and takes the first place. Then the same processes are done for the rest of the alternatives. As happened in the descend distillation process, here also two alternatives came across with the same score and have been put into the sub-matrix. After the calculation it is understood that those two alternatives take the second position. Same situation occurred for the rest of the alternatives and they are also put in a submatrix. After the calculation it is understood that they also share the same position which is the third one. According to ascend distillation matrix, final situation is seen in Table 12.

\section{Table 12}

Ascend distillation matrix (Final Situation)

\begin{tabular}{cc}
\hline Place & Alternative \\
\hline 1 & Open Minded Mentality \\
2 & Brainstorming \\
2 & Benchmarking \\
3 & Feedback \\
3 & Relationship with SCE \\
\hline
\end{tabular}

After checking, it is understood that the ordering process is right. The most important stimulators of open innovation are Feedback and Relationship with Supply Chain Elements. This result is not surprised because the nature of open innovation requires interaction with business partners as mentioned above. The requirement to produce new ideas that is Brainstorming and making comparison to see your real place that is Benchmarking follow them. Maybe the most surprising result in this study is Open Minded Mentality takes the last place. Because it is for sure that from bottom to top, manager or blue collar-employee is not open minded, then open innovation cannot be thought; stability is inevitable. 


\section{Conclusion and Discussion}

According to this study, the factors, which are determining and fostering the open innovation process have been determined based on the implementation of ELECTRE III. For scoring process, an online interview has been made with the export-import manager of a tractor company who manufactures tractor engines and parts. Open innovation can be assumed as a new issue and the researches about it are still being made and will be kept made. It is known that, especially for some sectors and for the companies which are striving for sharing new ideas and open to share what they have, open innovation is useful. The importance of it is for sure, but it is not certain that it is really good for firms in long term. In this research five factors have been determined and investigated under two criteria which are the types of open innovation; inbound and outbound. Based on the factors, the most important ones are Relationship with Supply Chain Elements and Feedback. Throughout history, organizations always liked to be careful before they did anything and listened to their customers before deciding to make any change in their product, process or service. Also, open innovation requires an interaction and communication with other partners in business. That is why those two factors are naturally the most important ones.

This study has limitations such as trying the model with only one company. This company is a manufacturing company, so the results may show difference in other sectors such as the ones in service. Factors and criteria could be enough but for further researches, they may be increased to get more details. Also other multi criteria decision making models could be used and made comparisons.

\section{References}

Battisti, G., Gallego, J., Rubalcaba, L., \& Windrum, P. (2015). Open innovation in services: knowledge sources, intellectual property rights and internationalization. Economics of Innovation and New Technology, 24(3), 223-247.

Chesbrough, H., Sohyeong, K., \& Agogino, A. (2014). Chez panisse: building an open innovation ecosystem. California management review, 56(4), 144-171.

Chesbrough, Henry W. (2006). Open Business Models: How to Thrive in the New Innovation Landscape. Boston: Harvard Business School Press.

Cheng, C. C., \& Huizingh, E. K. (2014). When is open innovation beneficial? The role of strategic orientation. Journal of Product Innovation Management,31(6), 1235-1253.

Collins, L. (2006). Opening up the innovation process. Engineering Management Journal, 16(1), 1417.

Coras, E. L., \& Tantau, A. D. (2014). Open Innovation-The Good, The Bad, The Uncertainties. The USV Annals of Economics and Public Administration, 14(1), 38-47.

Gianiodis, P. T., Ettlie, J. E., \& Urbina, J. J. (2014). Open service innovation in the global banking industry: Inside-out versus outside-in strategies. The Academy of Management Perspectives, 28(1), 76-91.

Granstrand, O., \& Holgersson, M. (2014). The challenge of closing open innovation. ResearchTechnology Management, 19-25.

Hu, Y., McNamara, P., \& McLoughlin, D. (2015). Outbound open innovation in bio-pharmaceutical out-licensing. Technovation, 35, 46-58.

Huang, S., Chen, J., Wang, Y., Ning, L., Sutherland, D., Zhou, Z., \& Zhou, Y. (2015). External heterogeneity and its impact on open innovation performance. Technology Analysis \& Strategic Management, 27(2), 182-197.

Kaynak, R., \& Maden, M.O. (2012). Expansion of boundaries on innovation: Open innovation. Ekonomik ve Sosyal Araştırmalar Dergisi, 8(1), pp.31-47.

Kondev, G., Tenchev, D., \& Vasileva, P. (2014). An open innovation model in the context of improving the competitiveness of the chemical and metallurgical industries. Journal of Chemical Technology and Metallurgy, 49(5), 515-519. 
Martinez, M.G. (2014). Co-creation of value by open innovation: Unlocking new sources of competitive advantage. Agribusiness, 30(2), pp.132-147.

Michelino, F., Lamberti, E., Cammarano, A., \& Caputo, M. (2015). Measuring open innovation in the bio-pharmaceutical industry. Creativity and Innovation Management, 24(1), pp.4-28.

Paik, J., \& Chang, H.J. (2014). Open innovation strategies of smartphone manufacturers: External resources and network positions. International Journal of Industrial Engineering, 21(5), 252-270.

Pauolose, H., \& Nair, S. (2015). Open innovation in emerging markets: A business model perspective. Journal of Promotion Management, 21(1), pp. 1-12.

Pellegrini, L., Lazzarotti, V., \& Manzini, R. (2014). Open innovation in the food and drink industry. Journal of Agricultural \& Food Industrial Organization, 12(1), 75-94.

Pena, R.R., \& Oliveras, K.G. (2007). Use and Evaluation of ELECTE III/IV.

Robbins, S.P., \& Judge, T.A. (2009). Organizational Behavior. Prentice Hall, London.

Robbins, S.P., \& DeCenzo, D.A. (2008). Fundamentals of Management. Prentice Hall, London.

Salter, A., Criscuolo, P., \& Ter Wal, A. L. (2014). Coping with Open Innovation: responding to the challenges of external engagement in R\&D.California Management Review, 56(2) 77-94.

Shamah, R.A.M., \& Elsawaby, S.M.M. (2014). Trust as a nucleus key for open innovation. Journal of Business and Retail Management Research, 9(1), 110-127.

Vienna Tourist Board (2014). http://www.prnewswire.com/news-releases/worldwide-brainstormingproject-vienna-tourist-board-targets-open-innovation-245976121.html. Access Date: 02 May 2015.

Wallin, M. W., \& Von Krogh, G. (2010). Organizing for Open Innovation:: Focus on the Integration of Knowledge. Organizational Dynamics, 39(2), 145-154.

Whelan, E., Conboy, K., Crowston, K., Morgan, L., \& Rossi, M. (2014). The role of information systems in enabling open innovation. Journal of the Association for Information Systems, 15(Special Issue).

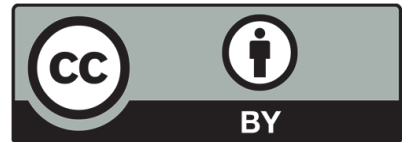

(C) 2016 by the authors; licensee Growing Science, Canada. This is an open access article distributed under the terms and conditions of the Creative Commons Attribution (CC-BY) license (http://creativecommons.org/licenses/by/4.0/). 